\title{
Inequality of Opportunity: Reply to Pedro Rosa Dias and Erik Schokkaert
}

\author{
Ravi Kanbura and Adam Wagstaff $\mathrm{b}^{*}$ \\ ${ }^{a}$ Charles H. Dyson School of Applied Economics and Management, and Department of Economics, Cornell \\ University, 301-J Warren Hall, Ithaca, NY 14853-7801, USA \\ ${ }^{\mathrm{b}}$ Development Research Group, The World Bank, 1818 H Street, NW, Washington DC 20433, USA
}

March 2015

\section{Acknowledgments}

The findings, interpretations and conclusions expressed in this paper are entirely those of the authors, and do not necessarily represent the views of the World Bank, its Executive Directors, or the governments of the countries they represent.

* Corresponding author: Adam Wagstaff. Development Research Group, The World Bank, 1818 H Street, NW, Washington DC 20433, USA. Tel: +1 202473 0566, awagstaff@worldbank.org 
We welcome the comments of Pedro Rosa Dias and Erik Schokkaert on our Editorial as a means of stimulating further debate on the usefulness of estimates of inequality of opportunity, especially for policy purposes. Our responses to their comments are in three categories. First, they broadly agree with many of our criticisms of the Paes de Barros et al. approach to measuring inequality of opportunity, but they say that these criticisms are already well appreciated in the literature. We beg to differ. Given our knowledge of work in policy settings, we believe that strong health warnings are in order. Second, we feel they do not sufficiently engage with a number of our points, including on talent and on luck. Third, while we agree with them that a strong focus on the income-health gradient leaves out many other considerations, we would nevertheless continue to argue for this focus on pragmatic grounds in the realm of policy.

In our Editorial we focused on a strand of work emanating from the World Bank which was initially focused on Latin America. The strategy is to identify a small number of variables which can be identified as "circumstance", and for which comparable data is available across countries, and to elevate the extent of the variation in the chosen outcome variable (income, health, education) which can be attributed to these variables as being a measure of inequality of opportunity. The simplicity and replicability of the method, together with the influential role of the World Bank in policy analysis, has meant that this method is now being applied in the policy context to other regions of the world, and numbers for inequality of opportunity using this method are being produced routinely and compiled (see Table 2 in Brunori, Ferreira and Pergaine (2013)). Indeed, these numbers are then used in a next stage of analysis, for example whether inequality of opportunity so measured is causally associated with economic growth (Ferreira et al. 2014). We therefore believe that a strong note of caution is in order. 
The problem with the method, other than the obvious one that estimates of inequality of opportunity are driven by the lowest common denominator of which circumstance variables appear in surveys across all countries being compared, is of course that it produces at best a lower bound on inequality of opportunity. It produces an underestimate of "illegitimate" inequality and an overestimate of "legitimate" inequality, but with no handle whatsoever on the extent of under- or over- estimation. These points, as argued forcefully and rightly by Dias and Schokkaert, are recognized in the academic literature. Yet, in the policy context, despite the caveats of researchers, these numbers will be treated as point estimates. It is difficult to see how it could be otherwise, since a statement that the lower bound for inequality of opportunity is $25 \%$, say, is perfectly consistent with the claim that inequality of opportunity is in fact $100 \%$.

Both Dias and Schokkaert point to studies in the literature which supplement circumstance variables with effort variables, thereby leading to a decomposition of inequality of outcome into (i) that which is attributable to the circumstance variables (ii) that which is attributable to the effort variables and (iii) the residual. The first component gives a lower bound on inequality of opportunity while $100 \%$ minus the second gives an upper bound on inequality of opportunity. But confidence in these bounds depends on the interaction between circumstances and effort and the observables of effort (Ravallion 2015). There is the further question of what is in the residual—circumstance, effort or luck. Attributing the whole residual to circumstance will lead to an underestimate of inequality of opportunity; attributing all of it to effort will lead to an overestimate.

This then leads to the question of how luck is to be treated-circumstance or effort. We argue that, to use Dworkin's terms, 'brute' luck should count alongside circumstances not effort; in principle 'option' luck ought to count as effort, but because in many areas of 
health information is incomplete, and health promotion campaigns are blunted / distorted by advertising, it's unclear that all option luck should count as effort. The effects of brute luck are not (and cannot be easily) captured empirically, and it's hard to see how option luck could be separated into acceptable vs. unacceptable option luck. Pedro Rosa Dias agrees with us but says it's only Paes de Barros who assign luck to the responsibility set in the literature. In the rest of the empirical literature, luck is treated as unobserved heterogeneity. Erik Schokkaert says that in the literature luck is modeled as part of the residual but the residual also includes omitted circumstance and effort variables. Fleurbaey and Schokkaert suggest upper and lower bound estimates of unfair inequality based on whether the whole residual is or is not treated as an illegitimate source of inequality, as noted above.

We argue that talents and hence outcomes are constrained by innate talents over which we have no control and should be viewed as another circumstance. Our point, however, is that the effects of innate talents are not (and cannot be easily) captured empirically. Dias comments that Paes de Barros are alone in the literature in suggesting that talents be included in the effort set (Roemer, for example, argues that they should be part of circumstance). Schokkaert does not address this issue directly, but says empirical framework admits different ethical positions and also admits possibility of efforts and circumstances interacting. This is potentially more of an issue in education and income than in health.

One of our main points is that individual outcomes reflect the individual's own efforts and decisions, but also the efforts and decisions of other people, and we have little control - if any - over these. The efforts of others are not (and cannot be easily) captured empirically. Dias agrees with us for the case of people below legal age of responsibility but 
says that this criticism is well known. Schokkaert does not address this directly, although he admits the possibility of efforts and circumstances interacting for an individual. Dias seems to disagree that our claim is valid for adults too, but it is difficult to see how this argument can be made in general if there are peer effects in interaction. Relatedly, an individual's circumstances could also be the result of the interaction between the efforts of a number of individuals, as when a market equilibrium determines prices or location of production, and this becomes the circumstance for an individual purchasing food or looking for employment. These situations, which are surely pervasive, lead to an empirical problem in separating out circumstance from effort, but also a conceptual one. If we follow the circumstance doctrine and move to correct this illegitimate source of inequality, are we not violating the effort doctrine, that outcomes of effort are legitimate sources of inequality?

Our final point, which seems to have drawn most fire from the commentators, was made in the spirit of pragmatism and policy settings. If we cannot ever say how much inequality is unfair, why not focus instead on how much is - for sure - unfair and amenable to policy, namely the part of inequality that is systematically linked to socioeconomic status. In an interesting twist on our critique of Paes de Barros, both Dias and Schokkaert say that our proposal would only address part of illegitimate inequality. Schokkaert says that our proposal treats income/ socioeconomic status as only circumstance variable and implicitly accepts all other sources of inequality are fair - the proposal leads only to a lower bound. Dias says also that income-related inequality is only a lower bound, and he also questions whether it is more relevant for policy. He refers to Deaton as saying that the health-income gradient will reflect bad inequalities and good inequalities - it's just a correlation. Evidence from early childhood interventions shows gradient opens early in life, 
suggesting early interventions may be preferred to ex post remediation of socioeconomic inequalities. A return to concentration indices would be "rowing against the current."

We of course recognize and appreciate these criticisms. However, our points above vis-à-vis efforts of others, luck, and talent, lead us to believe that most inequality of outcome is inequality of opportunity and that empirically we will never be able to extract the small part of inequality not due to inequality of opportunity. Thus, for pragmatic policy purposes, it probably makes sense as a first cut to think of all inequality as inequality of opportunity. The merits of focusing on the income gradient are twofold. First, we know from well identified studies of the health effects of lotteries, old-age pensions and cash transfer programs that increases in income cause health improvements (Case and Wise 2004; Lindahl 2005; Baird et al. 2012); in fact, Lindahl's OLS and IV results using lottery winnings are not significantly different from one another, suggesting that much - if not most - of the income-health correlation reflects a causal relation running from income to health. Unless we are willing to argue that income inequality largely reflects inequalities in effort rather than inequalities in circumstances, it would seem that, while some may disagree with our claim that most inequality reflects inequality of opportunity, most will agree that the health-income gradient belongs to the subset of inequality that constitutes inequality of opportunity.

The second reason for focusing on the income gradient is that it ought for sure to be amenable to policy. Governments increasingly have the capacity to assess a family's means either through the tax system or through means-testing arrangements for public programs; by contrast, even in rich countries, governments do not typically routinely assess many other variables that one might include in the circumstance set. Moreover, governments have the tools to act on this information to redistribute income by changing the 
distributions of taxes and subsidies; the latter could include increasing the number of low-

income households with subsidized health insurance (Finkelstein et al. 2012). This does not say at all that we should not be trying to reduce inequalities in early childhood or even in utero (and progressive redistribution may help here as well). Nor that we should not be trying to reduce inequalities not associated with income. But we should be careful that the effort to provide fine estimates of circumstance does not become a detour which diverts our attention from tackling that part of inequality that is both agreed to be inequitable and remediable through existing policy instruments.

\section{References}

Baird, S. J., R. S. Garfein, C. T. McIntosh and B. Ozler (2012). "Effect of a cash transfer programme for schooling on prevalence of HIV and herpes simplex type 2 in Malawi: a cluster randomised trial." Lancet 379(9823): 1320-1329.

Brunori, P., F. H. G. Ferreira and V. Peragine (2013). Inequality of opportunity, income inequality and economic mobility: some international comparisons. The World Bank, Policy Research Working Paper Series, 6304.

Case, A. and D. A. Wise (2004). Does Money Protect Health Status? Evidence from South African Pensions. Perspectives on the economics of aging. NBER Conference Report series. Chicago and London, University of Chicago Press: 287-305.

Ferreira, F. H. G., C. Lakner, M. A. Lugo and B. Ozler (2014). Inequality of opportunity and economic growth : a cross-country analysis. The World Bank, Policy Research Working Paper Series, 6915.

Finkelstein, A., Sarah Taubman, Bill Wright, Mira Bernstein, Jonathan Gruber, Joseph P. Newhouse, Heidi Allen, Katherine Baicker and Oregon Health Study Group (2012). "The Oregon Health Insurance Experiment: Evidence from the First Year." Quarterly Journal of Economics 127 3: 1057-1106.

Lindahl, M. (2005). "Estimating the Effect of Income on Health and Mortality Using Lottery Prizes as an Exogenous Source of Variation in Income." Journal of Human Resources 40 1: 144-168.

Ravallion, M. (2015). Equity and Development: Revisiting the 2006 World Development Report Proceedings from IEA Jordan Roundtable on Shared Prosperity. K. Basu and J. E. Stiglitz. London, Palgrave McMillan. 